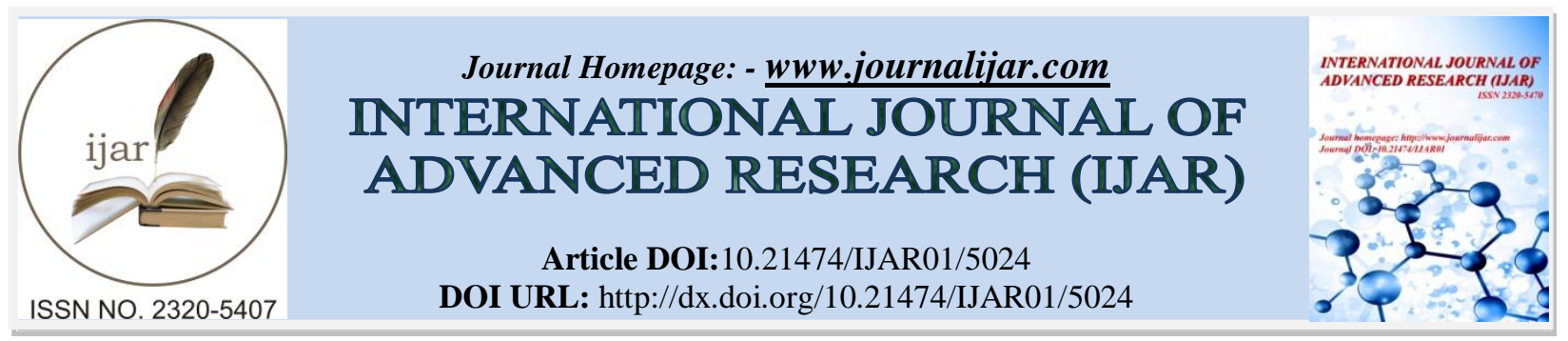

RESEARCH ARTICLE

\title{
ANALYSIS OF PUBLIC RELATONS OF TATA MAIN HOSPITAL AND ITS PUBLIC OPINION EXPRESSED ON SOCIAL MEDIA NETWORKING SITES.
}

Dr. Ramesh Chandra Pathak.

Associate Professor, Amity School of Communication, Amity University Rajasthan.

\section{Manuscript Info}

\section{Manuscript History}

Received: 29 May 2017

Final Accepted: 31 June 2017

Published: July 2017

Keywords: -

Healthcare, TMH, Social Media,

Hospital, Public Relations, PR Practices,

Consumer Rights, Customers, Internet,

Convergence, Facebook

\section{Abstract}

This research paper is an effort to study the Health Service practices of Tata Main Hospital. How effective approach of PR practices is following by Tata Main Hospital in the era of social media is also a major area of investigation. This research paper is also trying to find out various public opinions expressed on social media networking sites. We are all aware that the contemporary government is more conscious about the health services in India. The private hospitals are also supposed to provide better health facilities as they claim. TMH is also providing continuous healthcare facilities but with due course of time it has enhanced its medical customer care and public relations or not it is also a part of research. An effective PR practices are the demand of time and it is also behind the successful functioning of the hospital. Now a day's health service providers must be aware that our customers are equipped with internet revolution, social media benefits and convergence. They are also aware about the government health care schemes, policies and consumer rights. Therefore, this research paper is an effort to investigate the analysis of public Relations of Tata Main Hospital and its public opinion expressed on social media networking sites.

Copy Right, IJAR, 2017, All rights reserved.

\section{Introduction: -}

Indian Health Services is facing many challenges with several deficiency and shortcomings. The health services are becoming more and more costly in private hospitals while government hospitals are lacking basic infrastructure. The cost of health services by private hospitals are increasing day by day but they are unable to provide good customer care and public relations to the patients. The most of private hospitals are hungry for money without following proper human rights and sympathy. The developing country like India has tremendous pressure to improve basic medical facilities, health and sanitation and to improve health infrastructure but it should not be on the cost of human values as the most of private hospitals are doing.

Tata Main Hospital (TMH) is situated in Jamshedpur. Its main branch is in Bistupur area of Jamshedpur along with its six sub branches. TMH was mainly established to provide healthcare services to the employee of Tata Steel. In the recent years Tata Steel has extended its services for non-Tata Steel workers and their belongings. Tata Steel was founded in 1907 and TMH in 1908.TMH is equipped with all facilities and medical advancements. Its secondary clinics are in Sakchi, Baridih, South Park, Kadma, Sonari and Sidhgora scattered around in Jamshedpur city. TMH is also offering several training programs. TMH has well equipped OPD as well as emergency services for outside 
visiting patients and for employees. It has well equipped diagnostic services which includes CT, MRI, Pathology, Radiology, ICU, Children Ward, Gynecology and other allied medical services like TMH offers intensive care to its patients through Critical Care Unit, Intensive Care Unit, Pediatric Intensive Care Unit, Burns Care Unit, Intermediate Medical Care Unit and High Dependency Unit. MTMH is also located at the walking distance from $\mathrm{TMH}$. It has multi-specialty general ward. TMH is providing many medical facilities to its customers. Its community relations are extended in several states including Jharkhand, West Bengal, Odisha and Chhattisgarh. TMH is spreading awareness through several medical camps in near residing communities especially in Adivasi community and tribes.

\section{Objective of research: -}

1. This research paper is trying to find out various public opinions expressed on social media networking sites.

2. The contemporary government is more conscious about the health services in India so, this research paper is also trying to find out participation and customer services by private hospital in India.

3. The private hospitals are also supposed to provide better health facilities as they claim so, this is major research problem.

4. TMH is also providing continuous healthcare facilities but with due course of time it has enhanced its medical customer care and public relations or not it is also a part of research problem and investigation.

5. An effective PR practices are the demand of time and it is also behind the successful functioning of the hospital.

6. Now a day's health service providers must be aware that our customers are equipped with internet, social media benefits and convergence. Regarding such developments what is the status of private hospitals.

7. Consumers of healthcare are also aware about the government health care schemes, policies and consumer rights. Therefore, this research paper is an effort to investigate these upper mentioned research problems.

\section{Importance of Research: -}

1. The importance of research is that This research paper is trying to find out various public opinions expressed on social media networking sites.

2. The contemporary government is more conscious about the health services in India so, this research paper is also trying to find out participation and customer services by private hospital in India.

3. The private hospitals are also supposed to provide better health facilities as they claim so, this is major research problem.

4. TMH is also providing continuous healthcare facilities but with due course of time it has enhanced its medical customer care and public relations or not it is also a part of research problem and investigation.

5. An effective PR practices are the demand of time and it is also behind the successful functioning of the hospital.

6. Now a day's health service providers must be aware that our customers are equipped with internet revolution, social media benefits and convergence. Regarding such developments what is the status of private hospitals.

7. Consumers of healthcare are also aware about the government health care schemes, policies and consumer rights. Therefore, this research paper is an effort to investigate these upper mentioned research problems.

\section{Review of Literature: -}

Secondary data collected from various sources like from libraries, various research journals, books and reports of several e-portals, social media and blogs. Study of National Health Policy and its guidelines are also part of review of literature. Several researches published related to healthcare sectors are also part of study. Scholarly articles about various governmental policies are also part of literature review.

\section{Hypothesis: -}

The reach of healthcare facility to all citizens in India is very vital and sensitive issue. Now a day's health service providers must be aware that our customers are equipped with internet, social media benefits and convergence. Consumers of healthcare are also aware about the government health care schemes, policies and consumer rights. In such scenario expectations are very high. TMH is providing healthcare facility but with changing time its medical customer care and public relations are also expected to be customer friendly. There are also possibilities that in few next year's customer may ignore such type of hospitals which is handling their patients very carelessly. The private hospitals are also supposed to provide better health facilities as they claim. An effective PR practices are the demand of time and it is also expected behind the successful functioning of the hospital. 


\section{Research Methodology: -}

The study is explanatory in nature and employs secondary research work. The study is also exploratory as it explores the relevance and usefulness of public relations in TMH. Numerous studies have pointed out that private hospitals have witnessed a tremendous development in the past few years in terms of their number, employment of advanced technology, quality of services and facilities delivered as well as number of admissions. The instrument is very useful in measuring customer's perception about the service quality dimensions of an organization based on five determinants namely, Tangibles, Reliability, Responsiveness, Assurance and Empathy. The instrument tries to measure the gap between customer's expectations from an organization and their opinion about the actual services delivered.

\section{Analysis and Interpretations: -}

Hospitals have become super specialized and technologically advanced. PR is an essential part of any organization because according to British Institute of Public Relations 'Public relations is the deliberate, planned, and sustained effort to establish and maintain mutual understanding between an organization and its publics" ${ }^{1}$.An effective PR practices are the demand of time and it is also behind the successful functioning of the hospital. Now a day's health service providers must be aware that our customers are equipped with internet revolution, social media benefits and convergence. Tata Main Hospital (TMH) is situated in Jamshedpur. Its main branch is in Bistupur area of Jamshedpur along with its six sub branches. TMH was mainly established to provide healthcare services to the employee of Tata Steel. In the recent years Tata Steel has extended its services for non-Tata Steel workers and their belongings. Tata Steel was founded in 1907 and TMH in 1908.TMH is equipped with all facilities and medical advancements. Its secondary clinics are in Sakchi, Baridih, South Park, Kadma, Sonari and Sidhgora scattered around in Jamshedpur city. TMH is also offering several training programs.

\section{Public Service of TMH: -}

TMH has well equipped OPD as well as emergency services for outside visiting patients and for employees. It has well equipped diagnostic services which includes CT, MRI, Pathology, Radiology, ICU, Children Ward, Gynecology and other allied medical services like TMH offers intensive care to its patients through Critical Care Unit (CCU), Intensive Care Unit (ICU), Pediatric Intensive Care Unit (PICU), Burns Care Unit (BCU), Intermediate Medical Care Unit (IMCU) and High Dependency Unit (HDU). Meherbai Tata Memorial Hospital (MTMH) is also located at the walking distance from TMH. It has multi-specialty general ward.

\section{Public Relations Initiatives: -}

TMH is providing many medical facilities to its customers. Its community relations are extended in several states including Jharkhand, West Bengal, Odisha and Chhattisgarh. TMH is spreading awareness through several medical camps in near residing communities especially in Adivasi community and tribes.

1. Family planning initiatives

2. Eye camps

3. Sneh Kendra, an HIV/AIDS initiative

4. Medical awareness and facilities through Lifeline express

5. Surgical camps

6. Disaster response

\section{Corporate Social Responsibility Initiatives by TMH: -}

Health camp in nearby tribal areas,

Health classes in educational institutes,

Infotainment based programs for community development,

Public forum discussion for medical awareness,

Health awareness activities for women workers,

Health awareness program for other cities like Gopalpur, Kalinganagar, Noamundi Mines,

Family planning and welfare activities in Jamshedpur and nearby,

Hepatitis B awareness among communities,

HIV awareness program and camps

Health and sanitation awareness in Basti and slum areas

Awareness and facilities for lady employees like their labor issues, vaccination, pre-and post-birth care.

\footnotetext{
${ }^{1}$ British Institute of Public Relations
} 


\section{Role of PR in TMH: -}

1. The systematical changes in health sector

2. The complex structure of hospital

3. The remarkable specialization in many fields

4. Language problem and bureaucracy

5. The changes in the conditions of the patient

6. Professionalization of hospital management

7. Restrictions on public sources and financial need

8. Besides these, there are other factors such as the improvements in the patient rights, information demand, etc.

9. The improvement of mass media, intensifying competition and the increase in the number of private hospitals.

\section{PR Tools Used by TMH: -}

1. Print Medium: Newspaper, Magazines, Brochures and pamphlets.

2. Electronic Medium: TV, Radio, Audio-Video, Infotainment etc.

3. Social Media: Facebook, Twitter etc.

Public opinion expressed on social media networking sites (Disclaimer: All the opinions expressed by public on social media networking sites are in natural form and this is not opinion of researcher)

\section{Public Opinion Expressed Regarding TMH on Facebook ${ }^{2}$ Daman Chandra Das:-}

star My wife is admitted in this hospital. She was suspected to have urine infection. We asked for cabin but due to some reason it was not available. Being the only n male attendant, I could not stay with the patient. So, I hired an attendant. My wife was given 3 saline's. When the 3rd saline was draining out I.e., at $4.10 \mathrm{am}$. Neither the attendant nor the sister was available. My wife walked along with the saline all by myself to station in darkness, her head was spinning though. At least an emergency Bell is expected. I had lots of expectations from a brand of Tata being an employee of Tata. But I am highly disappointed.

Like $\cdot$ Comment $\cdot$ about a month ago $\cdot 1$ Review $\cdot$

\section{Sumit Kr Mishra:-}

1 star no need to write selfless service, care first and all with big bold letters from the gate till the end... They were JN Tata's views... Where you discriminate your own employees while giving proper medical care and medicines, no proper waiting room for the people accompanying the patient ... Sorry \#TataMainHospital you are no longer ethically entitled to use those big glorious words of JN Tata

Like $\cdot$ Comment $\cdot$ about a month ago $\cdot$

\section{Ashok Upadhyay:-}

1 star I gave 1-star because that the minimum rating possible otherwise would have given -5 rating. It's a pity that even though Jamshedpur is growing at a fast rate, has a population of 1 million plus but still it lacks in average medical facility. Only one ram bharose hospital TMH is there where you are bound to take your patient in medical emergencies (others being Brahmananda Narayan Hrudalaya which u can say is out of the city). The behavior of the hospital staff(TMH) is pathetic, and their professional knowledge is beyond comparison. All senior doctors and senior nurses consider themselves as gods and goddesses and the patient as human guinea pigs to do all their experiments. With sugar level of 164 the nurses were trying to give insulin to my mother but I stopped her coz I have that bare minimum knowledge that it is given only when sugar level is beyond 300 . So be careful and very alert about the treatment in TMH otherwise your near and dear ones can very well land in ICU and CCU from general ward. I have seen patient was given insulin with blood sugar 160 and she landed up in CCU due to sugar level dropping to very low level. I hope my post helps

Like $\cdot$ Comment $\cdot$ about 9 months ago $\cdot 1$ Review $\cdot$

\section{Preeti Kumari:-}

3 stars in this hospital doctors are good but protocol I didn't like Like $\cdot$ Comment $\cdot 14$ hours ago $\cdot 1$ Review .

\footnotetext{
${ }^{2}$ https://www.facebook.com/pages/Tata-Main-Hospital/291356840923760
} 


\section{Santosh Kumar:-}

4 stars Thanks to all doctors medical and nursing staff and all supporting staff

Like $\cdot$ Comment $\cdot$ about 9 months ago $\cdot 2$ Reviews .

\section{Rabindra Pradhan:-}

2 stars Mostly trainee doctors not good behave with patient staff are not proper behavior infrastructure is well. Seeking for money.

Like $\cdot$ Comment $\cdot$ about a year ago $\cdot 1$ Review $\cdot$

Manish Kumar Singh:-

2-starDoctor take time to examine the patient and also a big false statement about patients' careless doctor Like $\cdot$ Comment $\cdot$ about 12 months ago $\cdot 1$ Review $\cdot$

\section{Biplav Chandra Das:-}

3 star All things are very good but one things are so hurting this was sis security guard used UN parliament language Like $\cdot$ Comment $\cdot$ about 2 years ago $\cdot 8$ Reviews .

\section{Pradip Kumar Chatterjee:-}

4 star All Jamshedpur civilian and surrounding people are depending on TMH due to near Jamshedpur not a hospital is available like $\mathrm{TMH}$.

Like $\cdot$ Comment $\cdot$ about 2 years ago $\cdot 2$ Reviews $\cdot$

\section{Neeraj Nayan:-}

1 star very pathetic service by the Nurses on duty in 3B.

Like $\cdot$ Comment $\cdot$ about 2 years ago $\cdot 11$ Reviews $\cdot$

\section{Rina Kiran:-}

5 -star बहुत ही अच्छे से देखभाल की बेवसथा है, सफाई अति उत्तम है

Like Comment $\cdot$ about 2 years ago 5 Reviews $\cdot$

Public Opinion Expressed Regarding TMH on www.glassdoor.co.in ${ }^{3}$

Current Contractor - Sterile Processing Technician in Tallahassee, FL (US)

Doesn't Recommend, Negative Outlook. I have been working at Tata Main Hospital as a contractor.

Pros: -

Changes can be made if you talk to the right person. If the team works together progress could possibly be made.

\section{Cons: -}

Dealing with a lot of people who just don't care. Management barely manage or knows how to manage. The one who care are over worked, stressed out, and eventually leaves. Barry receive any time off, or vacations time, but management is always out.

Advice to Management: Stop hiring friend and hire someone that is willing to do the work. Consider quality care to be a priority

\section{Public Opinion Expressed Regarding TMH on INDIAN CONSUMER COMPLAINTS FORUM ${ }^{4}$ Mukes85 :-}

My brother admitted on 29/10/2010 due to spine injury and he has paralysis in his leg and partial paralysis in hands. Then he was able to respirate and talk smoothly. Dr. F B Singh said that he had to implant plates by operation as early as possible. Operation was postponed on 1st November 2010 due doctor was on leave on Sunday. Before operation a doctor said to me that he might been taken to CCU for 4-5 days and it would cost Rs.10000/- per day. I said "ok". After operation, he was able to respirate. He was taken to CCU on 1st Nov. after operation. On 2nd Nov

\footnotetext{
${ }^{3}$ https://www.glassdoor.co.in/Reviews/Tata-Main-Hospital-Reviews-E521257.htm

${ }^{4}$ https://www.consumercomplaints.in/complaints/tata-main-hospital-jamshedpur-east-singhbhumjharkhand-c483366.html
} 
morning when all family members are at home and my brother's friend was there the hospital authority had decided to shift him in ward without taking any consent from us and at CCU noticeboard on 9:30 am, 2nd Nov updated my brother's condition was critical. We were happy because he was transferred to ward but by afternoon he was feeling uneasy in breathing. We complained it to doctor he switched off his mobile and not taken any action we were panicked and phone to GM of the hospital and finally doctors came after 4 hours and my brother had been taken to $\mathrm{CCU}$ and he was taken on ventilation. From next day doctors started cursing one Dr. Majumdar said that my brother was never able to walk "uskejeene ka kyafayda"(His life is without value). Whenever i asked him technical question about my brother health their replies were cursing only. After 28 days on ventilation almost and Rs.3-4 lac spent and listening such statement we decided to take risk and decided to shift to Cuttack. On 29th Nov on ventilation we had shifted the hospital authority had not given MRI report and other report the then i was not there. My old aged father went with ambulance to Cuttack when doctor from Cuttack want to talk to Dr. F B Singh he switched off his phone and he denied talking. Amazingly ventilation was removed on 2/12/2010 in Cuttack. Doctors of Tata Main Hospital made money from us, we are a middle-class family we have taken loans and credit for paying bills and doctors of TMH have done duty of recovery agent only. During CCU period in TMH by listening such cursing word my brother tried cutting his ventilated pipe several times. Doctors provoke him to do suicide. These are doctors? and when I was going to Resident Medical Officer for estimate he said it would take 3-4 days because his typist was on leave if $\mathrm{u}$ want now $\mathrm{u}$ should go to personal department and arrange a typist. What a funny management he and TISCO's Hospital is unable to arrange a typist. I have seen dengue patients those who are non-employees are 10-20 days in CCU because they(Hospital) are earning from them. This is big Hospital in Jamshedpur. But is it a Hospital? 9 Comments Updated: May 21, 2017

Andy4u_13 on Oct 13, 2011: -

I completely agree with Mukesh who had posted the bad service at TMH. I had a similar experience in which the concerned doctor was quite rude. When someone goes to a doctor, he at least expects a little care and concern from the Docs side. Here I found none of that. The doctor was arrogant and stomped around his cabin with anger when I requested him for some advice. I will not take names here but this is surely not the way to treat a patient. A person who trusts you completely and is ready to get operated by you. I accept the fact that TMH is probably overcrowded and short staffed but still a little care from the doctor's side does help. I have respected the TATAs all my life and as a resident of Jamshedpur know the services that they provide to the public in general. Still this experience has left a bad impact on the way I used to think about the Hospital. What I really am angry about is that the Doctor treats you like he is doing you a big favor.

\section{Sanjaykppp on Feb 17, 2012: -}

$\mathrm{Hi}$, I am fully agreeing with you. We also had a very bad experience with TMH. Even the patient was employee of Tata Steel itself. My Father was admitted in TMH 2-3 times in past one year for the same type of issue. Every time TMH doctors advised for Blood, $\mathrm{x}$ ray, ultrasound test etc. But after all the tests while asking for an update they were saying everything is fine. no any problem at all. but in the blood test clearly its showing the all enzymes levels were not in the range. after that in Jamshedpur other hospital we visited and the found the problem with the same type of diagnosis process and the suggested for urgent surgery. Already i asked question to TMH admin team that why not their doctors were able to find out the issue. they don't have skills. why they are playing with the life of person? we need to publish the TMH great work in everywhere so that the maximum person knows about the TMH culture.

Ishu143 on Jun 28, 2012: -

TMH is the only higher center at Jharkhand. Majority of high risk patient rush to TMH. I think TMH catering very good services in spite of limited resources. It is not possible anywhere to satisfy everyone.

\section{P N NAIR on Feb 17, 2013: -}

I M.P.N. Nair, Ex-employee of Tata Steel would like to bring to your kind notice that my wife Late Valsala Nair was admitted on 31st December 2012 in ward no. 7B for the treatment of Viral pneumonia (as informed by the doctors). She was shifted to the Intermediate Care Unit on 2nd January 2013 with the complaint of Pulm. Oedema. She was under treatment of Dr. Sangitha Kamath and Dr. Amarpreet Paul in 7B ward. Whenever we approached the above referred doctors to know about the condition of the patient, their attitude was very casual. We never got proper reply from them. On 8th January 2013, she was again shifted to the ward from the IMCU and she was discharged on 11th January 2013. On 12th January 2013 despite being brought to the Emergency in an unconscious state, she was not admitted to the ICU. From 12th January 2013, onwards she was under the treatment of Dr Niraj. I 
am sorry to state that being a doctor by profession his behavior was very rude and arrogant towards the patient and the patient's relatives (e.g. just before being shifted to the ICU on 21st January 2013 when she was gasping for breath, in Hindi he told her to close her mouth else insects would enter her mouth. He also said that she was normal and was just acting. Minutes later Dr. B.S. Rao saw her condition and advised to shift her to the ICU where she passed away on 24th January 2013). From 14th January 2013 Dr. Niraj was experimenting with my wife's condition and had a very unprofessional approach (e.g. when her condition was deteriorating, my son approached him to attend the patient but he misbehaved with him). I saw my wife suffering and struggling for life in this hospital day by day. I am sorry to state that the treatment given by the doctors and the behavior of the nurses has gone down from bad to worst. They were reluctant to provide medication when it was desperately needed. It was the same hospital where my daughter's 7th month baby survived nine years back. From the day, my wife was admitted she kept on telling us that she will not survive because she felt that the treatment given and the approach of the staff was not at all caring and irresponsible in their approach (especially during night shift). I hope you will take necessary measures to help built patient and their relatives' confidence by giving proper treatment for any type of cases. Even though for us it is being a permanent loss which can't be compensated in any way.

\section{Skdb on Feb 4, 2016: -}

$\mathrm{TMH}$ is the worst private hospital I have ever visited. The doctors and other staff are very rude and insulting towards patients and their relatives. More ever they totally lack the desired knowledge and skills needed for their profession. I would advise that if you want to live never visit TMH or your days are over. The worst hospital in India and the world.

\section{AnnieSK on Mar 16, 2016: -}

The medical profession is supposed to be one of selflessness and humility. As a kid, I aspired to become a doctor just listening to stories or reading books of doctors who were treated next to God. However, my recent experience has shattered all these notions. My mother was admitted for a laparoscopic cholecystectomy (lab chole). The first thing that strikes you is the sheer negligence of the nurses. There are patients screaming around when trainees are made to inject, or an old lady lying in her own bed of urine, while the attendant is nowhere to be found. The AC is at its minimum, and no one is around to modify the temperature. Patients are shivering, constantly requesting, but in vain.

Secondly, is the attitude with which the nurses or sometimes even doctors on rounds answer to your queries. On one hand, they put up boards stating that a patient is entitled to question the staff regarding medication or any other query regarding his/her medical condition. While on the other hand, they ignore your questions or answer them in the briefest way possible. When I requested to consult the doctor after my mother's operation was over, I was told that since my relative had already met him once, there was no need of consulting him again.

On the day of discharge, we were told that even though the formalities would start in the morning, it would be midafternoon by which she could be discharged. Strangely, no one kept us updated on the progress. It was only around 2 when I went to the sister's room to check on the status, I was told the bills have already been sent to the counter. Isn't it basic decency to keep the patient's family informed?

Overall, it wasn't the best experience that a patient can recollect. A middle-class family struggles a lot to make ends meet, and when they do spend amounts that burn a hole in the pocket, they at least expect to get a fruitful return. You tend to lose faith in humanity and the medical profession when you go through such situations.

\section{Bajranga on Jul 24, 2016: -}

I agree to your complaint this hospital is very poor treatment, doctor's and nursing staff. Only make money all the concern staff as nurses to RMO.

\section{Ranojit Palit on Feb 20, 2017: -}

I am Ranojit Palit, My grandfather Nikhil Mitra was admitted in TMH on 11 February 2017 and the TMH Dr. Gaguly and Dr. Ashish were looking after him in next day he was perfectly fine and he was talking with us he was having breathing problem so oxygen pipe was put in mouth and then they put blood in body but first they will see that the blood is circulating but no they continuously supply 2 bottle but blood was not circulating and then after dr. Told that he had pneumonia in lungs and he is not able to breathe but dr. Told that pneumonia was cause in TMHCCU And dr. Has also accepted it But after 2 day when my mom go to hospital the doctor told that the patient 
is not able to take any medicine and he is also not detoring from night and dr. Told my mom that what I will do I will process or not Then my mother told yes you have process And Dr. Asstt told that the patient will not survive more than $24 \mathrm{hrs}$. but he survived then Then my grandfather was stable for 4 to 5 day and dr. Told that the pipe of lungs are block .then my mother sent a TMH doctor who was our friend she told that the pipe of lungs are block because of blood that they gave to the patient no medicine was going into the lungs to cure the pneumonia. But yesterday on 19 February 2017 there were Assistant doctor because it was Sunday they change a pipe and after 5 hrs. my grandfather dyed it was all doctor fault the bloody doctor killed my grandfather Dr. Gaguly and Dr. Ashish and their assistant it's a bad and worst hospital. Please take any action of it please.

Joy250363 on May 21, 2017: -

I Shri Joy Banerjee working in Karim City College admitted in JGMH in ward 2A on 15.05.2017 for total thyroid actomy under the surgeons Dr. Ashis Kumar and Dr. Prasanna Dora and I think they are outstanding surgeons and an asset of TMH. I felt there very comfortable. Service of nurses towards the patients were outstanding especially Sister Aprna, Sushmita who were kept total care on me. Only the discrepancy is found in cleanliness and AC systems. Please modify them and rest is ok. Thanks to the management of TMH.

\section{Conclusion: -}

An effective PR practices are the demand of time and it is also behind the successful functioning of the hospital. Now a day's health service providers must be aware that our customers are more aware than earlier. Most of the social media networking site comments are showing negative services by TMH. The patients and their belongings who had taken the health services facility from TMH they are sharing negative comments about the administration of TMH. However, few respondents are totally unsatisfied and few are remembering the days of 70's and 80's regarding the quality of doctors and health services factors. Most of the belongings of patients are unsatisfied and anger over the behavior of doctors and nurses. Their primary allegations are that doctors are unskilled and very rude in behavior. In general ward during their routine visit administration creates all suspense regarding medical reports and they talk very rude. Even some patients claimed that doctors are considering themselves as god and nurses as goddess. The several opinions expressed by service men associated with TMH on another social networking sites narrates about the work culture of TMH. Few respondents also expressed their anger about the rude and inhumane behavior of security guards of TMH. Target respondents also reported about continuously misbehavior with the belongings of the patients. Majority of views expressed and reported about the rude and inhumane behavior of overall mechanism.

This study concludes that TMH is associated with very large and prestigious organization and it should maintain the dignity of her parent organization. As we are all aware that in India first PR effort was done by the house of TATA's. It has also been seen during the investigation that lots of people have respect about Tata Steel but they cannot blindly trust on TMH. The public opinions expressed on social media is the reflection of negative health services, public relations and customer care by TMH. India is technically very aware country and no private hospital can fool patients with inhumane angle. Only those hospitals will sustain here those which will provide healthcare facilities with human values.

\section{References: -}

1. Mitchell, T.T. (2004). Patient Satisfaction more important than ever addressing the critical criteria. Health Care Collector, 18 (1), pp. 10-11.

2. Osborn, M. (2009). Taking Measure of Health Care Public Relations: A Case Study Analysis of the Riverview hospital women's pavilion Grand Opening.

3. Marina, M. (2009). Communication- An Important Management task in the hospital market. Journal of Management \& Marketing, 3 (1), 9-12.

4. Tengilimoglu, D., Yesiltas,M., Kisa,A., \& Dziegielewski, S.F.(2007). The Role of Public Relations Activities in Hospital Choice. Health Marketing Quarterly (The Haworth Press) Vol. 24, No. 3/4, 2007, pp. 19-31

5. Kirdar,Y.(2007). The Role of Public Relations for Image Creating in Health Services: A Sample Patient Satisfaction Survey. Health Marketing Quarterly (The Haworth Press) Vol. 24, No. 3/4

6. Gaurav, S., Ajay, S. \&Shashsi,S. (2014). Hospital Management and Organising Function: A Study of Perceptions of Hospital Staff in Public and Private Hospitals in India. Abhinav National Monthly Referred Journal of Research in Commerce \& Management. Vol 3, Issue 6 
7. Vani, G.R. (2014). Hospital Administration. Retrived from: shodhganga.inflibnet.ac.in/bitstream/10603/30995/12/12_chapter5.pdf

8. Raman, V.A. \&Björkman, J.W. (1996). Public/Private Partnership in Health Care Services in India. Research study funded by the Indo-Dutch Programme on Alternatives in Development (project 5.3.96). Retrived from: www.pppinharyana.gov.in/ppp/sector/health/report-healthcare.pdf

9. V. R. Muraleedharan, Ph.D. (1999). Characteristics and Structure of the Private Hospital | Sector in Urban India: A Study of Madras City. Small Applied Research Paper 5. Partnerships for Health Reform

10. Arya, S.B. (2012). A Comparative Study of Public and Private Health Services in Mumbai Region Availability and Utilisation Pattern. Synopsis of Ph.D. thesis. Retrived from: shodhganga.inflibnet.ac.in:8080/jspui/bitstream/10603/.../14_synopsis.p..

11. Unknown author. Hospital Management \& Administration. Retrived from :// careerguidance.ind.in/.../career-inhospital-management-and-adminis

12. Nikky. (2009). The Role of Public Relations Departments in Hospitals Retrived from :// nikkytai.blogspot.com

13. Unknown author. (2010). Retrived: https://www.scribd.com/doc/44647234/Public-Relation-Needs-Importance

14. Gordon, C.G. \& Kathleen, S.K. (1999). Public Relations Expertise and Organizational Effectiveness: A Study of U.S. Hospitals. Journal of Public Relations Research, 11(2), 143-165

15. British Institute of Public Relations

16. https://www.facebook.com/pages/Tata-Main-Hospital/291356840923760

17. https://www.glassdoor.co.in/Reviews/Tata-Main-Hospital-Reviews-E521257.htm

18. https://www.consumercomplaints.in/complaints/tata-main-hospital-jamshedpur-east-singhbhum-jharkhandc483366.html

19. http://www.tatamainhospital.com/

20. www.tatasteel.com/ 